\title{
Killing two birds with one stone: How do Plant Viruses Break Down Plant Defenses and Manipulate Cellular Processes to Replicate Themselves?
}

\author{
Pedro Filho Noronha Souza ${ }^{1,2, *, \dagger}$ and Fabricio Eulálio Leite Carvalho ${ }^{1, \uparrow}$ \\ ${ }^{I}$ Department of Biochemistry and Molecular Biology, Center of Science, Federal University of Ceara, Fortaleza, Ceara, Brazil \\ ${ }^{2}$ Nebraska Center for Virology, Department of Plant Pathology, University of Nebraska Lincoln, Lincoln, Nebraska, United \\ States
}

Received: February 19, 2019 / Accepted: March 15, 2019

(C) Korean Society of Plant Biologists 2019

\begin{abstract}
As simple organisms with a parasite nature, viruses have become masters in manipulating and subvert cellular components, including host proteins and organelles, to improve viral replication. Therefore, the understanding of viral strategies to manipulate cell function disrupting plant defenses and enhancing viral infection cycles is fundamental to the production of virus-resistant plant lines. After invading susceptible plants, viruses create conditions that favor local and systemic infections by suppressing multiple layers of innate host defenses while use cellular machinery to own benefit. Viral interference in interlinked essential cellular functions results in phenotypic changes and disease symptoms, which debilitates plants favoring infection establishment. Herein in this review, the novelty it will be the discussion about the strategies used by $(+)$ single strand RNA viruses to affect cellular processes and components to improve viral replication, in parallel to overcome plant defenses, favoring disease establishment by applying in one action using the same viral protein to coordinate viral replication and breaking down plant defense. This focus on plant-virus interaction was never done before, and this knowledge has the potential to help in the development of new strategies to produce resistant plants.
\end{abstract}

Keywords: Cellular manipulation, Plant defense, Plant host proteins, Plant viruses, $(+)$ RNA viruses, Viral replication

These authors contribute equally to this work.

*Corresponding author; Pedro Filho Noronha Souza

Tel : +55-85-33669823

E-mail : pedro.de-souza@unl.edu; pedrofilhobio@gmail.com

\section{Introduction}

Plants are in permanent contact with several microbial pathogens, such as fungi, bacteria, and viruses, which are responsible for several agricultural losses. Annually, the exposure of economically important crops to pathogens results in losses of millions of dollars (Savary et al. 2012; De León et al. 2013). Among plant pathogens, plant viruses have gained more and more attention. Until 2012, already had been registered 92 genera of plant viruses at the International Committee on Taxonomy of Viruses database (King et al. 2012). Plant (+) RNA viruses can infect several cultures with agronomic importance such as beans, soybean, tomato, peanut, cassava, wheat, rice, cucumber, potato, tobacco, barley, and peppers, which corroborate the importance of these pathogens in limitation of food production worldwide (Elvira et al. 2008; Scholthof et al. 2011; Hill et al. 2014; Kenyon et al. 2014; Shoup Rupp et al. 2016; Dempsey et al. 2017; Souza et al. 2017).

Plant infection by viruses results in several physiological and biochemical disorders, which early lead to symptom and disease establishment, and later, plant death and economic losses. The economic losses are the end of the way that begins with symptoms establishment. During viral infection, the shutting off the cellular function is critical for viruses induce symptoms and then continue with the infection. Chlorosis and mosaic formation are typical symptoms of viral infection in plants. These symptoms are the consequence of chloroplasts shut off induced by the virus (Li et al. 2006). For instance, Tobacco mosaic virus (TMV) induces chlorotic symptoms by two mechanisms; (1) accumulating coat protein on PSII core complex (Lehto et al. 2003) and (2) reducing the level of thylakoid membrane oxygen-evolving complex proteins (Abbink et al. 2002) during the replication process. These are great examples of how viruses can "kill two birds 
with one stone".

Viruses are obligatory parasites; to cause infection they have to be able to replicate in host cells. Once inside the cell, the viral $(+)$ RNAs are used as models to transcription and translation processes to produce new copies of RNAs and proteins, respectively. Then, these new viral particles are exported to neighbor cells up to the vascular system, leading to systemic infection (Nagy et al. 2012). Viral RNA genome encodes only a few proteins (3-10). Indeed, to complete the entire life cycle, viruses' require several cellular components (Table 1), such as proteins and metabolites, also referred to as cellular host factors.

During replication, viruses are counter-attacked by plant defense mechanisms, for example, RNA silencing (Garcia-Ruiz et al. 2010). However, despite a diverse set of plant defense mechanisms, in some cases, plants cannot prevent viral infection leading to disease establishment. Thus, the balance between these two different biological processes will be determinant to generate a compatible or incompatible plant-virus interaction. However, despite the importance of RNA viruses for crop productivity, deeper comprehension of the establishment of a compatible or incompatible plant-virus interaction is still lacking. Based on this fact, a question is raised: how do RNA viruses overcome plant defenses and replicate themselves and how they employ different host factors to reach this?

During evolution course, viral proteins acquired the ability to develop multiple functions. While they work in viral replication, viral proteins can display activities that lead to the breaking down of plant defense mechanisms. Viral proteins also can recruit plant cellular machinery to accelerate and complete viral replication (Harries et al. 2009; Huang et al. 2010; Huang et al. 2012; Hwang et al. 2013; Hwang et al. 2015). For example, coat viral protein (CP) possesses several additional activities beyond its canonical structural activity, including infectivity, pathogenicity and symptoms development (Weber et al. 2015). An additional example is the potyviral helper component proteinase (HC-Pro), which can recruit translation initiation factors to improve potyviral replication, besides displaying RNA silencing- suppressor activity, contributing to genome viral amplification, and being involved in aphid transmission (Garcia-Ruiz et al. 2010; Ala-Poikela et al. 2011).

In this review, we will discuss two aspects about plantvirus interaction (1) how plant RNA viruses achieve control of the cellular functions, proteins, and organelles, and use it to improve replication; (2) and how these viruses can break plant defense mechanisms to establish infection.

\section{Chloroplasts in Plant-virus Interactions: How do} Viruses Attack and Subvert Chloroplasts?

Chloroplasts are essential and abundant organelles in plants.
This organelle carries out one of the most important plants physiological processes: photosynthesis, which is responsible for providing energetic support (ATP and NADPH) to cope with pathogen infection (Nomura et al. 2012; Bhattacharyya et al. 2018; Souza et al. 2019). Based on the importance of chloroplasts to plants, we discuss in this section two important questions (1) why plant viruses have to break down chloroplasts functions and (2) how do they do this?

The importance of chloroplasts in plant defense is related to its ability to produce Reactive Oxygen Species (ROS). These ROS can act directly to prevent virus infection by induction of programmed cell death, and/or indirectly by inducing defense-related genes in the nucleus (Caplan et al. 2015). Thus, for successful infection, is imperative for viruses to suppress chloroplast-mediated defenses by employing several strategies, such as effector synthesis.

As skilled parasites, plant viruses can use the chloroplasts to improve their replication while shutting down processes that can be considered a threat. For example, TMV infection, which occurs outside of chloroplasts, is followed by CP (coat protein) accumulation at the PSII complex in thylakoids membranes and thus inhibition of electron transport within and starting at PSII. As a result, chloroplasts suffer impairment in the energetic balance involving light absorbance and metabolic energy, causing photoinhibition (Hodgson et al. 1989). Besides that, viruses can also interact with chloroplast proteins and induce the formation of membranes vesicles in improving viral replication. This viral-derived vesicle also generates severe alterations in chloroplast morphology, impairing its functions to plants (Liu et al. 2014; Li et al. 2016).

Virus-chloroplast interaction is critical for the development of typical disease symptoms during virus infection, such as changes in chloroplast structures, reduction of photosynthesis efficiency and reduction of chlorophyll levels (Shimura et al. 2011; Liu et al. 2014; Souza et al. 2017). The origin of viral symptoms is quite complex and different sources have been implicated in this process; however, it has been suggested that the primary source for symptoms arising are alterations in the normal function of the chloroplast, which produce chlorosis and mosaic (Rahoutei et al. 2000).

Viruses' effects on chlorophyll metabolism are an essential aspect that has to be considered in symptom development during the plant-virus interaction. In most cases, initial symptoms of viral infection on leaves are the appearance of yellow patches, white spots and the mosaic formation (Shimura et al. 2011; Liu et al. 2014; Souza et al. 2017). These symptoms are the result of virus interference in chlorophyll metabolism, leading to its degradation, affecting photosynthesis (Liu et al. 2014). Recently published studies with viruses from different families and different plant species report the drastic reduction in chlorophyll levels during compatible plant-virus interaction (Kundu et al. 2013; 
Rys et al. 2014; Souza et al. 2017).

The interference in chloroplast morphology and chlorophyll metabolism is the first part of a grand strategy developed by viruses. At this point, with disarmed chloroplasts, plants can do nothing to avoid viral replication in the chloroplast. Viruses induced a decrease in chlorophyll levels, which in turn result damage in photosystems and hence in the entire chloroplast machinery. This is also an important strategy to prevent ROS production. Changes in chlorophyll content are evident in studies that compare susceptible and resistance to the same viruses. For example, a recently published paper involving Cowpea severe mosaic virus (CPSMV, genus Comovirus) infection in susceptible cowpea (Vigna unguiculata) plants evidenced a reduction of 32 and $40 \%$ in chlorophyll $b$ and $a$, respectively, in comparison to resistant plants (Souza et al. 2017). In this work, it is clear that the changes in chlorophyll are important steps for symptom development and disease establishment. Up to date, two possible explanations about how viruses can interfere with the normal metabolism of chlorophyll were provided by two independent research groups.

The first mechanism was reported by Shimura and collaborators (Shimura et al. 2011) and involves RNA silencing of plant genes by the viruses. In this study, the authors showed an isolate of Cucumber mosaic virus carrying a YsatRNA (CMV-YsatRNA). This is interesting because CMVYsatRNA does not replicate in the chloroplasts but even though has a specific sequence complementary to chloroplast
mRNA of tobacco magnesium chelatase subunit I (Table 1 ChlI, a key enzyme in chlorophyll synthesis) inducing mRNA degradation by the own plant system resulting in severe chlorosis and mosaic establishment.

Liu and co-authors (Liu et al. 2014) proposed the second mechanism. In this case, the authors used the African cassava mosaic virus (ACMV genus Begomovirus) a DNA viruses; however, the discussion of this point is still relevant. These authors reported that mosaic phenotype coincides with upregulation of genes involved with chlorophyll degradation, followed by the reduction in the content of chlorophyll in leaves. In this study, the authors also reported the expression increase in two genes related to pheophytinase (PPH) and pheophorbide an oxygenase $(\mathrm{PaO})$ (Table 1), both involved in chlorophyll degradation. An interestingly point in this analysis is the fact that genes involved in chlorophyll synthesis as the gene for magnesium chelatase subunit I was drastically down-regulated. In this way, ACMV induces chlorophyll degradation and also avoid chlorophyll synthesis, leading to the mosaic establishment. This type of activity was not described yet to RNA viruses; however, the discussion and knowledge brought with it are important, because several RNA viruses induce the reduction of chlorophyll in plants during infection, and this mechanism might being applied for some RNA viruses even though is described yet.

The disarming of chloroplast functions is the first step of virus strategy during infection. The second step happens after or while the viruses cause irreversible damages in

Table 1. Cellular proteins manipulated by plants viruses

\begin{tabular}{|c|c|c|c|}
\hline Organelle & Virus & Genus & Reference \\
\hline \multicolumn{4}{|l|}{ Chloroplasts } \\
\hline PS II proteins & TuMV & Potyvirus & Hodgson et al. (1989) \\
\hline Magnesium Chelatase & CMV & Cucumovirus & Shimura et al. (2011) \\
\hline $\begin{array}{l}\text { Pheophytinase } \\
\text { Pheophorbide A oxygenase }\end{array}$ & ACMV & Begomovirus & Liu et al. (2014) \\
\hline cPGK & $\mathrm{BaMV}$ & Potexvirus & Lin et al. (2007) \\
\hline \multicolumn{4}{|l|}{ Nucleus } \\
\hline SCE1 & TuMV & Potyvirus & Xiong et al. (2013); Revers et al. (2015) \\
\hline ALY & TBSV & Tombusvirus & Canto et al. (2006); Uhrig et al. (2004) \\
\hline Nuclear actin filaments & TVCV & Tobamovirus & Levy et al. (2013) \\
\hline KELP & ToMV & & Sasaki et al. (2009) \\
\hline Fibrillarin & $\begin{array}{l}\text { GRV, PVA, BaMV, } \\
\text { RSV, BBSV, BSMV }\end{array}$ & $\begin{array}{l}\text { Umbravirus, Potexvirus, } \\
\text { Tenuivirus, Tombusvirus, } \\
\text { and Hordeivirus }\end{array}$ & $\begin{array}{l}\text { Kim et al. (2007); Rajamali et al. (2009); } \\
\text { Chang et al. (2016); Zheng et al. (2015); } \\
\text { Semashko et al. (2012); Li et al. (2018) }\end{array}$ \\
\hline \multicolumn{4}{|l|}{ Endoplasmic Reticulum } \\
\hline RHP & BMV & Bromovirus & Liu et al. (2009); Diaz et al. (2012) \\
\hline Acyl-CoA biding protein & BMV & Bromovirus & Zhang et al. (2012) \\
\hline RAB-like protein & GRV & Umbravirus & Huang et al. (2001) \\
\hline \multicolumn{4}{|l|}{ Peroxisome } \\
\hline Pex19p & TBSV & Tombusvirus & Pathak et al. (2008) \\
\hline
\end{tabular}


chloroplasts. At this moment, viruses recruit the chloroplast proteins (Table 1) to work for their benefit during the replication process.

The chloroplast phosphoglycerate kinase (cPGK) (Table 1) protein is an important host factor involved in the replication of several plant viruses. The portion 3' UTR of the Bamboo mosaic virus (BaMV genus Potexvirus) genomic RNA specifically interact with cPGK driving viral RNA to replicate into chloroplasts. Indeed, interactions between BaMV 3' UTR and cPGK drive formation of membrane-derived vesicles in chloroplasts, which is a safe place to BaMV replication (Lin et al. 2006). These vesicles produced by BaMV result in a morphological change in chloroplast preventing it to play function in plant defense. The importance of this interaction was confirmed by using mutants silenced to $\mathrm{CPGK}$ protein, which presented reduced BaMV RNA accumulation (Lin et al. 2006; Cheng et al. 2013). Indeed, cPGK was confirmed as an essential plant factor required for replication of a range of plant viruses. This is a clear case of how viruses "kills two birds with one stone". In this case, by assaulting only one protein, cPGK, in one action BaMV can improve its replication and inhibit chloroplast functions in plant defense.

In another case, Arabidopsis plants with natural recessive resistance gene rwm1 against Watermelon mosaic virus (WMV, genus Potyvirus) and encoding a mutated version of cPKG, exhibited WMV replication affected and plants did not develop any disease symptom (Lin et al. 2006; Ouibrahim et al. 2014).

Plant viruses are also specialized in the use of chloroplast membrane systems to produce vesicles with three main goals: (1) to bring together all essential cellular supplies to virus replication. (2) to protect its RNA molecules from silencing events activated by plants. (3) to leave the chloroplasts and move to other organelles during cell-to-cell infection spreading process (Laliberté et al. 2010).

Other interesting example about how viruses "kill two birds with one stone" comes from Potato virus X (PVX) replication, which occurs in the chloroplast. During replication, PVX CP accumulates in high levels in chloroplasts. Besides, PVX CP can interact with the plastocyanin proteins, and as a result of this interaction, chloroplast suffers from many morphological alterations, damage, and inhibition of chloroplasts functions. To confirm the importance of CP-plastocyanin to PVX infection, mutants of Nicotiana benthamiana plants to plastocyanins present reduced or even absence of PVX CP accumulation in chloroplast although the total levels of $\mathrm{CP}$ in the cell did not change. This result that the accumulation o PVX CP and its interaction with plastocyanin are important to PVX infection associated symptoms by causing damage in chloroplasts (Qiao et al. 2009).

Several different published studies strongly support this viral strategy to infect chloroplast proposed here over the years aimed to understand the effects of viral infection in chloroplasts and how this affects infection establishment. Following this strategy, the examples presented in this section, easily support the central idea of this review that virus can "kill two birds with one stone" by attacking chloroplast and shutting down its roles in defense while using it improves viral replication and symptoms develop.

Plant $(+)$ strand RNA viruses are masters in hijack host factors and cause several morphological rearrangements in organelles leading to the production of vesicles in infected cells to improve viral replication. Besides chloroplasts, viruses can manipulate other organelles such as the nucleus, endoplasmic reticulum (ER), mitochondria, and peroxisomes (Table 1) and some aspects of this manipulation will be discussed in the following topics.

\section{Nucleus - What is the Password to Get in?}

The nucleus is the site for eukaryotic genetic material, where it is kept separated from the cytoplasm. The transport of different molecules into the nucleus is extremely regulated by proteins that form the nuclear pore complex (NPC) essential for transport in and out nucleus. Nucleus entrance regulation is essential to keep normal nuclear functions and, hence overall cellular functions. Besides, the tight regulation of NPC mediated transport consists of an important and effective antiviral response. Nevertheless, viruses might cheat this regulation of nucleus-cytoplasmic pathways and access nuclear functions crucial for its replication (Qiao et al. 2017; Walker et al. 2017; Li et al. 2018).

The virus-nucleus interaction is amply reported in the literature, mainly because, virtually, all viruses including DNA viruses, retroviruses, and RNA viruses require interaction with the nucleus in order to achieve replication. The interaction of DNA viruses and retroviruses is completely understandable once they need nuclear factors to complete their replication process. On the opposite way, $(+)$ strand RNA viruses replicate the process in the cytoplasm. Consequently, an important question could be raised here: As such, why RNA viruses do need to interact with the plant nucleus? What is the biological relevance for this interaction? The answers for these questions are still conflicting, especially because several works involving enucleated cells about the important/function of the nucleus in replication of $(+)$ strand RNA viruses realized with enucleated cells showed that $(+)$ strand RNA viruses can replicate normally under such conditions, but and the enucleation in these experiments, in some cases, virus replication was also decreased (Evans et al. 1980). Thus, a consensus regarding the roles played on nuclear metabolism during $(+)$ strand RNA viruses seems to be a hard task to address.

To comprehend the importance of virus-nucleus interactions 
to virus replication, an important question needs to be solved: what is the "password" that allows viruses to access the nucleus? Possibly, viruses can employ two distinct strategies to bypass this limitation: (1) viruses can develop proteins with the signal sequence to the nucleus; (2) they can develop proteins able to interact with nuclear host proteins and subsequently to reach within the nucleus (Table 1). A great example of the first strategy is reported for potyviruses that have proteins with the nuclear signal. Potyviruses possess two nuclear inclusion protein an (NIa) and b (NIb), which interacts with several nuclear host proteins and therefore might induce assembly of a viral replication complex in the host nucleus (Revers et al. 2015). For instance, it has been postulated that the interaction of TuMV-NIb with nuclear factors such as SCE1 is an important event to TuMV replication. To confirm the importance of this interaction for TuMV replication, TuMV carrying a mutant form of Nib that fails in interact with SCE1 is not able to replicate in $N$. benthamiana (Xiong et al. 2013).

Direct interaction with nuclear proteins is an important strategy to access nuclear environment and is employed by several plant viruses (Evans et al. 1980; Kim et al. 2007; Li et al. 2018). To different studies, one point is the consensus for $(+)$ RNA viruses: viral proteins can traffic within and without nucleus by using NPC interaction. This movement is very important to virus life cycle because either viral proteins are required for any replication step in the nucleus (i.e., bind viral RNA to transcription factors) or in a cytoplasmic step (i.e., encapsidation) proteins can be recruited to place which is required (Hiscox 2007). Also, this ability to come in and out from the nucleus is a clear example of how virus "kills two birds with one stone". Because the interaction with nuclear protein helps viral replication while interferes with nuclear function in plant defense.

The interaction between tomato plants and Tomato bushy stunt virus (TBSV, genus Tombusvirus) provides consistent data to prove that viruses "kill two birds with one stone" (Fig. 1A). In these interactions, the protein p19 encoded by TBSV, which has a site of replication peroxisome, shown two essential functions for virus replication. First, p19 bind to ALY (an mRNA-export factor from the nucleus) leading to the redistribution of this protein from the nucleus to the cytoplasm, which results in shutting down of cell host protein synthesis and favor TBSV cell-to-cell movement. Second, the same p19 protein is transported from the cytoplasm to the nucleus by ALY and inhibit plant RNA silencing (i.e., the main plant antiviral immunity) preventing viral RNA degradation (Uhrig et al. 2004).

\section{A}

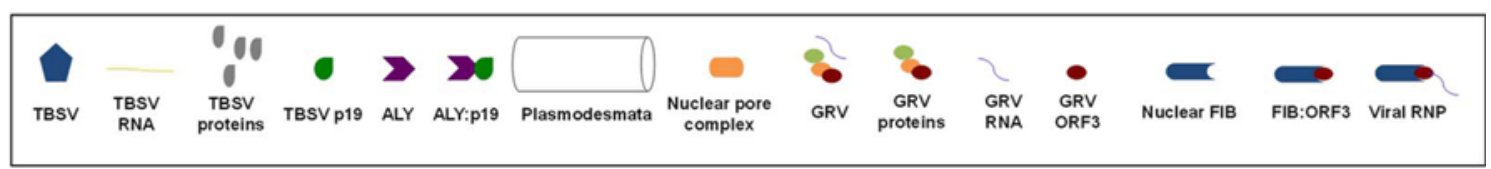

B

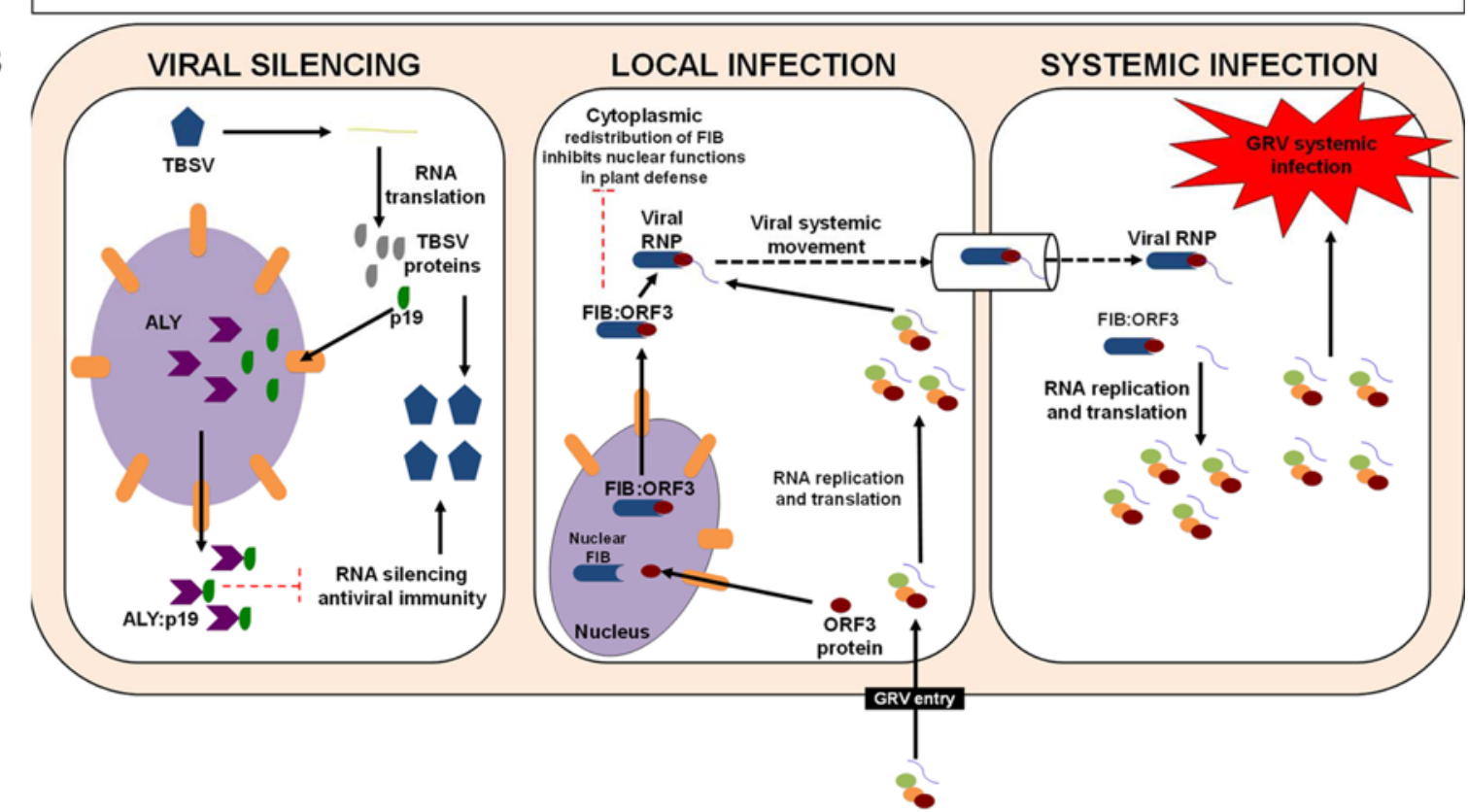

Fig. 1. Model showing how RNA viruses attack the nucleus to complete replication process or for movement. (A) p19 from TBSV, which replicates in cytoplasm, moves to nucleus to hijack ALY nuclear factor, to perform TBSV replication and preventing RNA antiviral immunity establishment. (B) GRV ORF3 protein moves from cytoplasm to the nucleus to assault nuclear fibrillarin protein. The fibrillarin protein is important for GRV vRNP particles movement throughout plasmodesmata. 
Two studies published previously (Matsushita et al. 2001; Levy et al. 2013) provide strong pieces of evidence about how the virus, especially virus from Tobamovirus family, can impair nuclear functions. First, the P30, a movement protein encoded by Turnip vein clearing virus (TVCV, genus Tobamovirus), was unexpected localized in the nucleus during Arabidopsis thaliana infection. In the nucleus, the TVCV P30 was found interacting with actin filaments associated with chromatin to enhance TVCV movement from the initially infected cells. Sequencing data of TVCV P30 revealed the presence of an NLS domain. Point mutations inserted in NLS of the TVCV P30 result in complete blocking of P30 access to the nucleus and consequentially dramatic reduction in TVCV long-distance movement (Levy et al. 2013). Matsushita et al. (2001) reported that P30 protein from Tomato mosaic virus (ToMV, genus Tobamovirus) interacts with a transcriptional coactivator factor KELP to access nucleus and facilitate viral movement. KELP protein is an important coactivator factor involved with expression of defense-related genes, in that way, the subversion of KELP by ToMV to work on in viral movement makes this unavailable for the plant which in turn impair defense-related genes expression weakening plant defense. Therefore, in one shot ToMV uses a plant protein to moves and to inhibit plant defense, this is a clear example of "kill two birds with one stone".

During Groundnut rosette virus (GRV, Umbravirus) the ORF3 protein interacts with a nuclear protein to perform a cell-to-cell movement of GRV. The GRV is an uncommon virus, different from other plant viruses; GRV does not produce a coat protein, resulting in non-conventional virus particles in infected plants (Ryabov et al. 1998; Ryabov et al. 1999; Ryabov et al. 2001; Kim et al. 2007). To compensate for the lack of CP GRV produces the ORF3 protein, which is responsible for virus accumulation and mainly in cell-tocell movement (Ryabov et al. 1999; Ryabov et al. 2001). Interestingly, during GRV infection, ORF3 was found in the nucleus (Fig. 1 B), an unexpected address, because the GRV replication is completely restricted to the cytoplasm. However, analyses of the ORF3 shown two conserved domains called Arginine- and Leucine-rich domains, both essential to importing and nuclear localization, suggesting ORF3 protein traffic between nucleus and cytoplasm in infected cells (Ryabov et al. 1998; Ryabov et al. 1999). Kim et al. (2007) showed that ORF3 protein interacts with a nuclear protein called fibrillarin (FIB). In this study, pieces of evidence support the interaction of GRV protein was not related to viral replication, but instead linked to GRV long-distance movement and systemic infection. The ORF3 protein can move from the cytoplasm to the nucleus and them, rapidly, moves back to the cytoplasm. At the end of this movement cytoplasm/nucleus/cytoplasm of ORF3 recruits fibrillarin from the nucleus to cytoplasm. Once in the cytoplasm, fibrillarin works in the production of GRV ribonucleoproteins (RNP) (Fig. 1B) particles that are capable of perform longdistance movement (Kim et al. 2007).

The interaction of viral proteins with a plant nuclear FIB protein is not exclusive for Umbraviruses since many viruses from different families have acquired the ability to redistribute FIB protein from nucleus to cytoplasm. Among different viruses that can perform FIB redistribution are Rice stripe virus (RSV, Tenuivirus) (Zheng et al. 2015) and Barley stripe mosaic virus (BSMV, Hordeivirus) (Li et al. 2018). Studies involving these plant viruses strongly suggest that nuclear FIB protein possess great importance in plant $(+)$ strand RNA viral replication. The interaction of viral proteins with FIB is important for two reasons: (1) FIB is critical to longdistance movement (Fig. 1B), and (2) once virus redistribute FIB protein from nucleus to cytoplasm, the protein cannot display its function in mRNA to translation, in this way impairs cellular protein synthesis and any change to establish defense against viral infection.

Fibrillarin is essential for nuclear structure, nucleolus stabilization and in RNA metabolism. Also, fibrillarin is an important RNA binding protein able to interact with several types of RNAs such as snoRNA, snRNA, siRNA, and rRNA (Rakitina et al. 2011; Kalinina et al. 2018). The latter function is well explored by viruses to form RNPs particles important for viral movement. As such, when a viral protein interacts to FIB two important consequences to plants are notable: (1) nucleolus disassemble and loss of nuclear function (i.e., DNA replication and transcription), and (2) viral movement to health tissues leading to systemic viral spreading. Then, viruses kill two birds with one stone.

Based on that, it is clear the importance of affecting nucleus to viruses perform replication. So, viruses have developed two "passwords" to get into the nucleus and manipulate it to obtain success during infection (Fig. 1). Different from chloroplast (site of replication) viral function, apparently nuclear functions are more related to viral movement than to favoring viral replication, although the latter is not absent. The most important award to control cellular nucleus is to avoid the most important plant antiviral immunity, RNA silencing. Once virus destabilizes nucleus, plants cannot start RNA silencing events, and then viruses can conquer the new cells and entire tissues.

\section{Endoplasmic Reticulum - Multifunctional Organelle to Viruses}

The endoplasmic reticulum (ER) is essential to many cellular functions such as steroids synthesis, calcium storage, intracellular traffic, and when associated with ribosomes, forming rough 
$\mathrm{ER}$ is responsible for protein synthesis and sorting to others organelles (Verchot 2016a). These functions attributed to the ER make it one of the important plants addresses to viruses during infection. During infection establishment, viruses frequently provoke morphological and molecular alterations in ER, mainly in membranes to produce virus progeny (Verchot 2016b).

The ER can be handy for viruses by improving viral replication and movement. Due to the presence of machinery to produce proteins, ER is hijacked by viruses to working as "slave" in all steps of virus replication including RNA replication and translation, viral assembly, and transport to others organelles and egress from infected cells to colonize new healthy cells (Grangeon et al. 2012).

The main component of ER usurped by viruses is the membranes. By using ER membranes, viruses induce the formation of replication vesicles (RV) providing physical support to a coordinated translation and replication of RNA, also, to keep close cellular components necessary to efficient viral replication, such as tRNAs and nucleotides and proteins, for example. Additionally, RVs formed in the ER membranes are a safety environment acting as a shield protecting viral RNA from host immune defense (i.e., nucleases) ensuring a minimal or even no exposure of viral genome to cellular receptors that can initiate defense mechanisms (Cao et al. 2015; Romero-Brey et al. 2016; Verchot 2016a).

The most studied models of virus-induced membrane modification in ER are those analyzed during plant infection caused by viruses from Bromoviridae and Tombusviridae families (Restrepo-Hartwig et al. 1996; Cao et al. 2015). Regarding plant viruses belonging to the Bromoviridae family, Brome Mosaic Virus (BMV) and Cowpea chlorotic mottle virus (CCMV) are good models to understand how these viruses can cause morphological alterations in ER membranes.

During replication process, BMV replicates its RNA inside of a $60 \mathrm{~nm}$ spherule produced in ER-membranes, which is very close to the nucleus, whereas CCMV causes spherules in the ER lumen in perinuclear and peripheral portions (Kim 1977; Restrepo-Hartwig et al. 1996). On the other hand, the Beat black scorch virus (BBSV) belonging to the Tombusviridae family induces ER aggregation and vesiculation (Cao et al. 2015). Besides Bromoviruses and Tombusviruses, Potyviruses and Potexviruses also stimulate ER-membranes rearrangements leading to vesicle production with two goals (1) improve and protect virus replication process and (2) use these vesicles for intracellular movement (Grangeon et al. 2012; Hashimoto et al. 2015).

These membrane alterations provoked by viruses required a high consumption of cellular energy. To induce such modification viruses need to acquire control of the biochemical process of the cell. In addition, changes in fatty acids metabolisms and rearrangement of membranes are required (Diaz et al. 2012). Take control of these processes is vital for virus success; otherwise, there will be no replication. For example, Sharma and collaborators (Sharma et al. 2011) reported that the inhibition of sterol biosynthesis drastically reduces replication and infection process of Tombusvirus in yeasts and plants.

To access the whole potential of the ER and inhibit its function in plant defense, viral proteins have to interact with ER proteins to induce satisfactory changes. BMV is a great example to understand how plant viruses can use cellular proteins to control organelles and then replicate. In a sequential study Schwartz et al. (2002) and Schwartz et al. (2004) reported by using electron microscopy that BMV infection in yeasts leads to morphological alterations in ER membranes producing larger spherules with double-membranes; which are responsible to support BMV RNA replication (Schwartz et al. 2004). Also, recently, spherules-like structures were found in ER membranes of Nicotiana benthamiana plants infected with BMV (Bamunusinghe et al. 2011).

Experiments in yeasts showed that BMV 1a protein (a helicase-like protein) could interact with an ER protein called reticulon homology domain protein (RHP). RHP is a membrane protein essential for membrane biogenesis; in this way, by interacting with RHP, BMV induces replication vesicles formation enhancing its replication. To prove this idea, mutations introduced in protein 1a result inhibiting its interaction with RHP affects the ability to induce vesicles formation in ER leading to a dramatic reduction of BMV replication (Diaz et al. 2012). Also, when another approach was applied by complete depletion of RHP presence in yeasts no membrane rearrangements were detected and consequently inhibits BMV RNA replication was evaluated (Diaz et al. 2012).

Another particular and exciting mode of action of the viral protein to bind to the ER membrane was reported by Kusumanegara and coauthors (Kusumanegara et al. 2012). In this study, a p27 auxiliary protein from the Red clover necrotic mosaic virus (RCNMV, genus Dianthovirus) possesses two domains important to RCNMV replication in $N$. benthamiana. One of those domains in the N-terminal region is an amphipathic $\alpha$-helix that can be inserted in the ER membrane, which is responsible for $\mathrm{p} 27$ protein localization in the ER and hence RCNMV. However, this domain is not enough to guarantee RCNMV replication in the ER membrane. The second domain, nevertheless, cannot bind to the ER membrane but is required to induce the formation of the replication complex, and in that way stimulate RCNMV in ER membrane. Also, Mine et al. (2012) reported that p27 interacts with a heat shock protein $70 \mathrm{kDa}$ (HSP70) from ER to drive the formation of a 480-kDa-replication complex on ER. Also, the authors showed that when p27-HSP70 interaction 
is inhibited, p27 can form the complex. However, the complex is not functional, and RCNMV not happens. This result clearly shows the dependence of RCNMV of HSP70 to complete the replication process (Mine et al. 2012). By using the functions of HSP70, an essential protein involved in protein folding, this protein cannot display this role in ER protein synthesis; this could deeply impair protein synthesis.

Together these studies clarify and strengthen the hypothesis that plant viruses subvert ER membranes with at least three goals (1) to improve viral replication by bringing together all component required for viral replication; (2) to protect viral genome toward plant defense mechanisms (i.e., Ribonucleases and/or RNA silencing events); and (3) to impair the role of ER in cellular defense to virus, once ER works with viruses cannot act in cellular protein synthesis, for example. Viruses induce membrane rearrangement in ER and hijack proteins to maintain these abnormally morphologies. ER is an essential site of protein synthesis in the cells. Viruses take control of ER to produce viral proteins while inhibiting cell protein synthesis disarming cell defense and enhance viral infection.

\section{Peroxisomes - Power to Viruses}

In addition to chloroplasts, peroxisomes are a site of ROS production, which is essential for plant defense by HR establishment, local PCD, and activation of plant defense genes. Peroxisomes work in the $\mathrm{C} 2$ cycle producing ROS by the activity of glycolate oxidase enzyme (Huang et al. 2010; Liu et al. 2013; Huang et al. 2016). Regarding the two crucial functions displayed by peroxisome in plant defense; (1) energy production and (2) ROS production, there is no surprise viruses target them during the infection process.

Several studies report plant virus hijacking these organelles such as Tomato bushy stunt virus (TBSV, genus Tombusvirus), Cymbidium ringspot virus (CymRSV, genus Potexvirus), Melon necrotic spot virus (MNSV, genus Carmovirus), and Cucumber necrosis virus (CNV, genus Tombusvirus) in peroxisomes (Navarro et al. 2004; McCartney et al. 2005; Panavas et al. 2005; Gomez-Aix et al. 2015).

Peroxisomes are replication site for many Tombusviruses such as TBSV, CymRSV, and CNV that cause multivesicular bodies in peroxisomes by recruiting several plant host factors, actins filaments and synthesis of steroids (Nagy 2016). Those intracellular structures form vesicle in the peroxisome membrane with to accommodate inside replication proteins, replication supplies, viral genome, and channels linking this matrix with cytoplasm, and least protect the viral genome from plant defense (Navarro et al. 2004; McCartney et al. 2005; Panavas et al. 2005). To assume control of peroxisomes,
TBSV p33 has to interact with a host peroxisomal protein Pex19p (Pathak et al. 2008). Pex19p is an oleic acid-inducible protein with a farnesyl group added, which is vital for peroxisome biogenesis. The lacking Pexp19 result in the absence of peroxisome and mislocalization of peroxisomal matrix proteins to the cytosol (Meinecke et al. 2016).

The viral $\mathrm{p} 33$ is replication auxiliary protein, which together with p92pol RdRp protein is involved in TBSV RNA replication and induction of abnormal peroxisomal vesicles (Panavas et al. 2005; Pathak et al. 2008; Nagy et al. 2012). During TBSV infection p33 protein interact with Pex19p forming a complex host-viral protein called p33-Pex19, which address TBSV replication to the peroxisome. Based on the activity of Pex19, several membrane-bound vesicles are induced in peroxisome to form a replication vesicle. The interaction between p33 and Pex19 is driven by an mPTS (peroxisomal membrane targeting sequences) domain present in p33 leading to insertion in the peroxisomal membrane. Once the complex p33-Pex19 arrives in the peroxisome, the vesicle induction is started, and Pex19p remains until the complete formation of TBSV replication vesicle. At this moment, the p33-Pex19 complex is disassembled and p33 forms a new complex with p92pol, TBSV RNA replication is launched (Pathak et al. 2008; Nagy et al. 2012). To prove that $\mathrm{p} 33$ is the protein in charge during TBSV replication and the importance of interaction with Pex19p, in an elegant experiment Pathak and collaborators (Pathak et al. 2008), produced a mutant Pex 19p with signal sequence addressed to mitochondria rather than peroxisome, and as expected TBSV replication was done in the mitochondrial membrane, instead peroxisome as usual. This experiment proves the importance and dependence of TBSV replication of p33: Pex19. This information has a great value to be used as a biotechnological approach to producing plants resistant to TBSV infection.

The TBSV p33 is intriguing protein hidden by many unclear processes, for example, is reported that p33 could interaction with over 100-host protein (Serva et al. 2006; Mendu et al. 2010) as revealed by the proteomic approach. Not enough, p33 can be submitted to post-translational modifications (i.e., phosphorylation) by cellular machinery (Nagy et al. 2012), what is the objective of post-translational modification in a viral protein? This is a question without an answer yet, but we can propose that these may improve some aspects of TBSV replication and infection, besides to be a great example of how TBSV manipulates cellular machinery. TBSV p33 protein is an example that plant viruses evolve over the years to be masters in manipulating cellular to improve viral replication and disease establishment. Once, p33 can manipulate cellular process disarms any chance of cells starts with molecular mechanisms to prevent viral infection.

By using p33-Pex19 interaction, TBSV can "kill two birds 
with one stone" because when Pex19 works to TBSV guided by p33, Pex19 is not available to peroxisome functions, besides that the presence of vesicle lead to morphological alterations in peroxisome morphology, which in case might inhibit peroxisome function in photosynthesis ( $\mathrm{C} 2$ cycle) and energy production by inhibiting lipid metabolism.

\section{Concluding Remarks}

Plant cells have a sophisticated network responsible for recognizing and starting a defense mechanism against pathogens infections. The connection of organelles performs a fast and efficient response to infection. However, in some plant viruses' interactions, this sophisticated defense mechanism is not enough to plant overcome viral infection and prevent disease establishment. This occurs because over the evolution course plant viruses adapts itself to control cellular process with three main goals: (1) to use cellular components to improve and accelerate viral replication; (2) to protect viral genome from cellular defense mechanisms; and (3) likely the most important, while the virus uses cellular components, inhibits several cellular processes preventing cell starts their defense mechanisms to inhibit viral replication. Once the virus reaches the cytoplasm of cells, they can move virtually to all organelles and use its function to improve viral replications and this way destroying any change of plant counterattack viral infection.

The cellular options available for virus use are massive, allowing the virus to choice either organelles or protein to improve the replication process. Possibly, at the beginning of plant-virus interactions only proteins were used to improve viral replication. In this case, plant developed new proteins preventing viral usage and replication. However, viruses maybe evolved to overcome the plant defense, a result of this, now viruses can use plant protein and organelles. Even to subvert an organelle, viruses need to interact with a protein, which highlights the importance of the interaction of viral and plant proteins.

Based on the discussion in this review, we know there is a significant amount of knowledge concerning plant virus interaction. In some case, a simple mutation in a protein can provide broad-spectrum resistance against viruses without any collateral effects to plants. It is hoped the use of this knowledge soon can be used to transfer gene for crops plant leading to resistance to viruses. An excellent tool for this is the CRISPR-Cas9 (Zhang et al. 2018), which should be used to introduce specific mutations in plant protein resulting in resistance.

\section{Acknowledgements}

This study was supported by the following Brazilian institutions: CNPq (National Council for Scientific and Technological Development. Process Numbers: 308107/2013-6 and 306202/2017-4); CAPES (Coordination of Improvement of Higher Education. Toxinology) Project, Process number: 431511/2016-0) and Fundação Cearense de Apoio ao Desenvolvimento Científico e Tecnológico (FUNCAP). FELC is supported by FUNCAP/CAPES (Bolsista CAPES/BRASIL - Proc. 88887.162856/2018-00). We are very thankful for the English corrections made by Spc. Layla Colares Viana da Silva.

\section{Author's Contributions}

PFNS and FELC wrote the manuscript; PFNS made the figure; FELC made the table; FELC modified the language; PFNS collected the literature; PFNS provided the ideas. All the authors agreed on the contents of the paper and post no conflicting interest.

\section{References}

Abbink TE, Peart JR, Mos TN, Baulcombe DC, Bol JF, Linthorst HJ (2002) Silencing of a gene encoding a protein component of the oxygen-evolving complex of photosystem II enhances virus replication in plants. Virology 295:307-319

Ala-Poikela M, Goytia E, Haikonen T, Rajamaki ML, Valkonen JP (2011) Helper component proteinase of the genus Potyvirus is an interaction partner of translation initiation factors eIF(iso) $4 \mathrm{E}$ and eIF4E and contains a 4E binding motif. J Virol 85:6784-6794

Bamunusinghe D, Seo JK, Rao AL (2011) Subcellular localization and rearrangement of endoplasmic reticulum by Brome mosaic virus capsid protein. J Virol 85:2953-2963

Bhattacharyya D, Chakraborty S (2018) Chloroplast: the Trojan horse in plant-virus interaction. Mol Plant Pathol 19:504-518

Cao X, Jin X, Zhang X, Li Y, Wang C, Wang X, Hong J, Wang X, Li D, Zhang Y (2015) Morphogenesis of Endoplasmic Reticulum Membrane-Invaginated Vesicles during Beet Black Scorch Virus Infection: Role of Auxiliary Replication Protein and New Implications of Three-Dimensional Architecture. J Virol 89:61846195

Caplan JL, Kumar AS, Park E, Padmanabhan MS, Hoban K, Modla S, Czymmek K, Dinesh-Kumar SP 2015. Chloroplast stromules function during innate immunity. Dev Cell 34:45-57

Cheng SF, Huang YP, Chen LH, Hsu YH, Tsai CH (2013) Chloroplast phosphoglycerate kinase is involved in the targeting of Bamboo mosaic virus to chloroplasts in Nicotiana benthamiana plants. Plant Physiol 163:1598-608

Dempsey M, Riley D, Srinivasan R (2017) Insecticidal effects on the spatial progression of tomato yellow leaf curl virus and movement of its whitefly vector in tomato. J Econ Entomol 110:875-883

Diaz A, Ahlquist P (2012) Role of host reticulon proteins in rearranging membranes for positive-strand RNA virus replication. Curr Opin Microbiol 15:519-524

Elvira MI, Galdeano MM, Gilardi P, Garcia-Luque I, Serra MT (2008) Proteomic analysis of pathogenesis-related proteins (PRs) induced by compatible and incompatible interactions of pepper mild mottle virus (PMMoV) in Capsicum chinense L3 plants. J Exp Bot 59:1253-1265

Evans MR, Simpson RW (1980) The coronavirus avian infectious bronchitis virus requires the cell nucleus and host transcriptional factors. Virology 105:582-591 
Garcia-Ruiz H, Takeda A, Chapman EJ, Sullivan CM, Fahlgren N, Brempelis KJ, Carrington JC (2010) Arabidopsis RNA-dependent RNA polymerases and dicer-like proteins in antiviral defense and small interfering RNA biogenesis during Turnip Mosaic Virus infection. Plant Cell 22:481-496

Gomez-Aix C, Garcia-Garcia M, Aranda MA, Sanchez-Pina MA (2015) Melon necrotic spot virus Replication Occurs in Association with Altered Mitochondria. Mol Plant Microbe Interact 28:387-397

Grangeon R, Agbeci M, Chen J, Grondin G, Zheng H, Laliberte JF (2012) Impact on the endoplasmic reticulum and Golgi apparatus of turnip mosaic virus infection. J Virol 86:9255-9265

Harries PA, Park JW, Sasaki N, Ballard KD, Maule AJ, Nelson RS (2009) Differing requirements for actin and myosin by plant viruses for sustained intercellular movement. Proc Natl Acad Sci USA 106:17594-17599

Hashimoto M, Komatsu K, Iwai R, Keima T, Maejima K, Shirashi K, Yoshida T, Kitazawa Y, Okano Y, Yamaji Y, Namba S (2015) Cell Death Triggered by a Putative Amphipathic Helix of Radish mosaic virus Helicase Protein Is Tightly Correlated With Host Membrane Modification. Mol Plant Microbe Interact 28:675688

Hill JH, Whitham SA (2014) Control of virus diseases in soybeans. Adv Virus Res 90:355-390

Hiscox JA (2007) RNA viruses: hijacking the dynamic nucleolus. Nat Rev Microbiol 5:119-127

Hodgson RA, Beachy RN, Pakrasi HB (1989) Selective inhibition of photosystem II in spinach by tobacco mosaic virus: an effect of the viral coat protein. FEBS Lett 245:267-270

Huang TS, Wei T, Laliberte JF, Wang A (2010) A host RNA helicaselike protein, AtRH8, interacts with the potyviral genome-linked protein, $\mathrm{VPg}$, associates with the virus accumulation complex, and is essential for infection. Plant Physiol 152:255-266

Huang Y, Ma HY, Huang W, Wang F, Xu ZS, Xiong AS (2016) Comparative proteomic analysis provides novel insight into the interaction between resistant vs susceptible tomato cultivars and TYLCV infection. BMC Plant Biol 16:162-174

Huang YW, Hu CC, Lin NS, Hsu YH (2012) Unusual roles of host metabolic enzymes and housekeeping proteins in plant virus replication. Curr Opin Virol 2:676-682

Hwang J, Lee S, Lee JH, Kang WH, Kang JH, Kang MY, Oh CS, Kang BC (2015) Plant Translation Elongation Factor 1B $\beta$ Facilitates Potato Virus X (PVX) Infection and Interacts with PVX Triple Gene Block Protein 1. PLoS One 10:e128014

Hwang J, Oh CS, Kang BC (2013) Translation elongation factor 1B (eEF1B) is an essential host factor for Tobacco mosaic virus infection in plants. Virology 439:105-14

Kalinina NO, Makarova S, Makhotenko A, Love AJ, Taliansky M (2018) The Multiple Functions of the Nucleolus in Plant Development, Disease and Stress Responses. Front Plant Sci 9:132

Kenyon L, Tsai W-S, Shih S-L, Lee L-M (2014) Emergence and diversity of begomoviruses infecting solanaceous crops in East and Southeast Asia. Virus Res 186:104-113

Kim K (1977) An ultrastructural study of inclusions and disease development in plant cells infected by cowpea chlorotic mottle virus. J Gen Virol 35:535-543

Kim SH, Macfarlane S, Kalinina NO, Rakitina DV, Ryabov EV, Gillespie T, Haupt S, Brown JW, Taliansky M (2007) Interaction of a plant virus-encoded protein with the major nucleolar protein fibrillarin is required for systemic virus infection. Proc Natl Acad Sci USA 104:11115-11120

King AM, Adams MJ, Carstens EB, Lefkowitz EJ (2012) Virus Taxonomy: Classification and Nomenclature of Viruses, Ninth Report of the International Committee on Taxonomy of Viruses, London, Waltham, Academic Press

Kundu S, Chakraborty D, Kundu A, Pal A (2013) Proteomics approach combined with biochemical attributes to elucidate compatible and incompatible plant-virus interactions between Vigna mungo and Mungbean Yellow Mosaic India Virus. Prot Sci 11:1-15

Kusumanegara K, Mine A, Hyodo K, Kaido M, Mise K, Okuno T (2012) Identification of domains in p27 auxiliary replicase protein essential for its association with the endoplasmic reticulum membranes in Red clover necrotic mosaic virus. Virology 433:131-41

Laliberté J-F, Sanfaçon H (2010) Cellular remodeling during plant virus infection. Annu Rev Phytopathol 48:69-91

Lehto K, Tikkanen M, Hiriart J-B, Paakkarinen V, Aro E-M (2003) Depletion of the photosystem II core complex in mature tobacco leaves infected by the flavum strain of tobacco mosaic virus. Mol Plant Microbe Int 16:1135-1144

Levy A, Zheng JY, Lazarowitz SG (2013) The Tobamovirus Turnip vein clearing virus $30 \mathrm{~K}$ Movement Protein Localizes to Novel Nuclear Filaments to Enhance Virus Infection. J Virol 87:64286440

Li Y, Cui H, Cui X, Wang A (2016) The altered photosynthetic machinery during compatible virus infection. Curr Opin Virol 17:19-24

Li Y, Hong J, Xue L, Yang Y, Zhou X, Jiang D (2006) Effects of Broad bean wilt virus 2 isolate infection on photosynthetic activities and chloroplast ultrastructure in broad bean leaves. $\mathrm{J}$ Plant Physiol Mol Biol 32:490-496

Li Z, Zhang Y, Jiang Z, Jin X, Zhang K, Wang X, Han C, Yu J, Li D (2018) Hijacking of the nucleolar protein fibrillarin by TGB1 is required for cell-to-cell movement of Barley stripe mosaic virus. Mol Plant Pathol 19:1222-1237

Lin JW, Ding MP, Hsu Y-H, Tsai C-H (2006) Chloroplast phosphoglycerate kinase, a gluconeogenetic enzyme, is required for efficient accumulation of Bamboo mosaic virus. Nucleic Acids Res 35:424-432

Liu J, Yang J, Bi H, Zhang P (2014) Why mosaic? Gene expression profiling of African cassava mosaic virus-infected cassava reveals the effect of chlorophyll degradation on symptom development. J Integr Plant Biol 56:122-132

Liao YWK, Sun ZH, Zhou YH, Shi K, Li X, Zhang GQ, Xia XJ, Chen ZX, Yu JQ (2013) The Role of Hydrogen Peroxide and Nitric Oxide in the Induction of Plant-Encoded RNA-Dependent RNA Polymerase 1 in the Basal Defense against Tobacco Mosaic Virus. PLoS One 8:e76090

Matsushita Y, Deguchi M, Youda M, Nishiguchi M, Nyunoya H (2001) The tomato mosaic tobamovirus movement protein interacts with a putative transcriptional coactivator KELP. Mol Cells 12:57-66

Mccartney AW, Greenwood JS, Fabian MR, White KA, Mullen RT (2005) Localization of the tomato bushy stunt virus replication protein p33 reveals a peroxisome-to-endoplasmic reticulum sorting pathway. Plant Cell 17:3513-3531

Meinecke M, Bartsch P, Wagner R (2016) Peroxisomal protein import pores. Biochim Biophys Acta 1863:821-827

Mendu V, Chiu M, Barajas D, Li Z, Nagy PD (2010) Cprl cyclophilin and Ess1 parvulin prolyl isomerases interact with the tombusvirus replication protein and inhibit viral replication in yeast model host. Virology 406:342-351

Mine A, Hyodo K, Tajima Y, Kusumanegara K, Taniguchi T, Kaido M, Mise K, Taniguchi H, Okuno T (2012) Differential roles of Hsp70 and Hsp90 in the assembly of the replicase complex of a positive-strand RNA plant virus. J Virol 86:12091-12104

Nagy PD (2016) Tombusvirus-Host Interactions: Co-Opted Evolutionarily Conserved Host Factors Take Center Court. Annu Rev Virol 3:491-515

Nagy PD, Barajas D, Pogany J (2012) Host factors with regulatory roles in tombusvirus replication. Curr Opin Virol 2:691-268

Nagy PD, Pogany J (2012) The dependence of viral RNA replication on co-opted host factors. Nat Rev Microbiol 10:137-149 
Navarro B, Rubino L, Russo M (2004) Expression of the Cymbidium ringspot virus 33-kilodalton protein in Saccharomyces cerevisiae and molecular dissection of the peroxisomal targeting signal. J Virol 78:4744-4752

Nomura H, Komori T, Uemura S, Kanda Y, Shimotani K, Nakai K, Furuichi T, Takebayashi K, Sugimoto T, Sano S, Suwastika IN, Fukusaki E, Yoshioka H, Nakahira Y, Shiina T (2012) Chloroplastmediated activation of plant immune signalling in Arabidopsis. Nat Commun 3:1-18

Ouibrahim L, Mazier M, Estevan J, et al. (2014) Cloning of the A rabidopsis rwm1 gene for resistance to $\mathrm{W}$ atermelon mosaic virus points to a new function for natural virus resistance genes. Plant J 79:705-716

Panavas T, Hawkins CM, Panaviene Z, Nagy PD (2005) The role of the p33: p33/p92 interaction domain in RNA replication and intracellular localization of $\mathrm{p} 33$ and $\mathrm{p} 92$ proteins of Cucumber necrosis tombusvirus. Virology 338:81-95

Pathak KB, Sasvari Z, Nagy PD (2008) The host Pex19p plays a role in peroxisomal localization of tombusvirus replication proteins. Virology 379:294-305

Ponce De León I, Montesano M (2013) Activation of defense mechanisms against pathogens in mosses and flowering plants. Int J Mol Sci 14:3178-200

Qiao W, Medina V, Falk BW (2017) Inspirations on virus replication and cell-to-cell movement from studies examining the cytopathology induced by lettuce infectious yellows virus in plant cells. Front Plant Sci 8:1672-1681

Qiao Y, Li H, Wong S, Fan Z (2009) Plastocyanin transit peptide interacts with Potato virus $\mathrm{X}$ coat protein, while silencing of plastocyanin reduces coat protein accumulation in chloroplasts and symptom severity in host plants. Mol Plant Microbe Intract 22:1523-1534

Rahoutei J, García-Luque I, Barón M (2000) Inhibition of photosynthesis by viral infection: effect on PSII structure and function. Physiol Plantarum 110:286-292

Rakitina DV, Taliansky M, Brown JW, Kalinina NO (2011) Two RNA-binding sites in plant fibrillarin provide interactions with various RNA substrates. Nucleic Acids Res 39:8869-8880

Restrepo-Hartwig MA, Ahlquist P (1996) Brome mosaic virus helicaseand polymerase-like proteins colocalize on the endoplasmic reticulum at sites of viral RNA synthesis. J Virol 70:8908-8916

Revers F, García JA (2015) Molecular biology of potyviruses. Adv Virus Res 92:101-199

Romero-Brey I, Bartenschlager R (2016) Endoplasmic Reticulum: The Favorite Intracellular Niche for Viral Replication and Assembly. Viruses 8:1-26

Ryabov E, Oparka K, Santa Cruz S, Robinson D, Taliansky M (1998) Intracellular location of two groundnut rosette umbravirus proteins delivered by PVX and TMV vectors. Virology 242:303-313

Ryabov EV, Robinson DJ, Taliansky M (2001). Umbravirus-encoded proteins both stabilize heterologous viral RNA and mediate its systemic movement in some plant species. Virology 288:391400

Ryabov EV, Robinson DJ, Taliansky ME (1999) A plant virusencoded protein facilitates long-distance movement of heterologous viral RNA. Proc Nat Aca Sci USA 96:1212-1217

Rys M, Juhasz C, Surowka E, Janeczko A, Saja D, Tóbiás I, Schoczowski A, Barna B, Gullner G (2014) Comparison of a compatible and an incompatible pepper-tobamovirus interaction by biochemical and non-invasive techniques: chlorophyll a fluorescence, isothermal calorimetry and FT-Raman spectroscopy.
Plant Physiol Biochem 83:267-278

Savary S, Ficke A, Aubertot J-N, Hollier C (2012) Crop losses due to diseases and their implications for global food production losses and food security. Food Security 4:519-37

Scholthof KB, Adkins S, Czosnek H, Palukaitis P, Jacquot E, Hohn T, Hohn B, Saunders K, Candresse T, Alhquist P, Hemenway C, Foster GD (2011) Top 10 plant viruses in molecular plant pathology. Mol Plant Pathol 12:938-954

Schwartz M, Chen J, Lee WM, Janda M, Ahlquist P (2004) Alternate, virus-induced membrane rearrangements support positive-strand RNA virus genome replication. Proc Nat Aca Sci USA 101: 11263-11268

Serva S, Nagy PD (2006) Proteomics analysis of the tombusvirus replicase: Hsp70 molecular chaperone is associated with the replicase and enhances viral RNA replication. J Virol 80:21622169

Sharma M, Sasvari Z, Nagy PD (2011) Inhibition of phospholipid biosynthesis decreases the activity of the tombusvirus replicase and alters the subcellular localization of replication proteins. Virology 415:141-152

Shimura H, Pantaleo V, Ishihara T, Myojo N, Inaba JI, Sueda K, Burgyán J, Masuta C (2011) A viral satellite RNA induces yellow symptoms on tobacco by targeting a gene involved in chlorophyll biosynthesis using the RNA silencing machinery. PLoS Pathog 7:e1002021

Shoup Rupp JL, Cruz LF, Trick HN, Fellers JP (2016) RNAimediated, stable resistance to Triticum mosaic virus in wheat. Crop Sci 56:1602-1610

Souza PF, Silva FD, Carvalho FE, Silveira JA, Vasconcelos IM, Oliveira JT (2017) Photosynthetic and biochemical mechanisms of an EMS-mutagenized cowpea associated with its resistance to cowpea severe mosaic virus. Plant Cell Rep 36:219-234

Souza PFN, Garcia-Ruiz H, Carvalho FE (2019) What proteomics can reveal about plant-virus interactions? Photosynthesis-related proteins on the spotlight. Theor Exp Plant Physiol 31:227-248 https://doi.org/10.1007/s40626-019-00142-0

Uhrig JF, Canto T, Marshall D, Macfarlane SA (2004) Relocalization of nuclear ALY proteins to the cytoplasm by the tomato bushy stunt virus P19 pathogenicity protein. Plant Physiol 135:24112423

Verchot J (2016) How does the stressed out ER find relief during virus infection? Curr Opin Virol 17:74-79

Verchot J (2016) Plant Virus Infection and the Ubiquitin Proteasome Machinery: Arms Race along the Endoplasmic Reticulum. Viruses 8:1-20

Walker EJ, Ghildyal R (2017) Editorial: Viral Interactions with the Nucleus. Front Microbiol 8:951-955

Weber PH, Bujarski JJ (2015) Multiple functions of capsid proteins in $(+)$ stranded RNA viruses during plant-virus interactions. Virus Res 196:140-149

Xiong R, Wang A (2013) SCE1, the SUMO-conjugating enzyme in plants that interacts with NIb, the RNA-dependent RNA polymerase of Turnip mosaic virus is required for viral infection. J Virol 87:4704-4715

Zhang T, Zheng Q, Yi X, An H, Zhao Y, Ma S, Zhou G (2018) Establishing RNA virus resistance in plants by harnessing CRISPR immune system. Plant Biotchnol J 16:1415-1423

Zheng L, Du Z, Lin C, Mao Q, Wu K, Wu J, Wei Z, Xie L (2015) Rice stripe tenuivirus p2 may recruit or manipulate nucleolar functions through an interaction with fibrillarin to promote virus systemic movement. Mol Plant Pathol 16:921-930 